\title{
Peritoneal Dialysis in Pediatric Postoperative Cardiac Surgical Patients
}

\author{
Manoj Kumar Sahu ${ }^{1}$, Bipin $C^{2}$, Yatin Arora ${ }^{3}$, Sarvesh Pal Singh ${ }^{4}$, V Devagouru ${ }^{5}$, P Rajshekar ${ }^{6}$, Shiv Kumar Chaudhary ${ }^{7}$
}

\begin{abstract}
Background: We determined the prevalence of acute kidney injury requiring peritoneal dialysis (PD), the factors associated with early PD initiation, prolonged PD and mortality among pediatric postoperative cardiac surgical patients.

Materials and Methods: The hospital records of 23 children, aged 12 years or younger, who had undergone cardiac surgery and required PD subsequently, during a 1-year period were reviewed. Demographic data, intraoperative variables, and postoperative complications were compared between survivors and nonsurvivors of PD, between the short and long duration PD groups, and between the early and late PD initiation groups. Results: Six hundred and eight pediatric patients who underwent open heart surgery were enrolled in this study. 23 (3.78\%) of them required PD. When compared with survivors $(n=11)$, non survivors $(n=12)$ were more likely to have a higher serum procalcitonin $(p=0.01)$, higher serum potassium on day $2(p=0.001)$, day $3(p=0.04)$, day of termination of $\operatorname{PD}(p=0.001)$ and a lower urine output on day 3 of PD $(p=0.03)$. Prolonged PD was associated with time of PD initiation $(p=0.01)$, a higher postoperative serum creatinine on day $3(p=0.01)$ of PD initiation as well on the day of PD termination $(p=0.01)$ and the final outcome in terms of survival $(p=0.02)$. Factors significantly associated with an early PD initiation were CPB time $(p=0.04)$, sepsis $(p=0.02)$ and shorter PD duration $(p=0.003)$.

Conclusion: PD is very useful mode of renal replacement therapy among pediatric postoperative cardiac surgical patients. The intraoperative and postoperative variables have important association with the time of PD initiation, PD duration and patient survival.

Keywords: Cardiopulmonary bypass, Pediatric cardiac surgery, Peritoneal dialysis, Postoperative period

Indian Journal of Critical Care Medicine (2019): 10.5005/jp-journals-10071-23221
\end{abstract}

\section{INTRODUCTION}

Acute kidney injury (AKI) is a well-known complication which faces treatment challenges after pediatric cardiac surgery. ${ }^{1-3}$ Risk factors of $\mathrm{AKI}$ and the need for renal replacement therapy include young age, complex cardiac lesions, long cardiopulmonary bypass time, and a low cardiac output state after surgery. ${ }^{4-6}$ Although the choice of renal replacement therapy is controversial, ${ }^{7,8}$ Peritoneal dialysis (PD) has been shown to be useful because of the ease of application, effectiveness in fluid removal and avoidance of additional vascular access and anticoagulation. ${ }^{1-3,6-8}$ Many studies have documented the importance of young age as a determinant of AKI and PD after pediatric cardiac surgery. ${ }^{3-5}$ A retrospective analysis was performed in 23 young children aged 12 years or younger undergoing open heart surgery for congenital heart diseases. We determined the prevalence of $\mathrm{AKI}$ requiring $\mathrm{PD}$. We also determined the risk factors association with prolonged PD, early PD initiation and mortality.

\section{Materials and Methods}

Between July 2017 and August 2018, 726 children were admitted in our cardiac surgical intensive care unit (CSICU) after undergoing cardiac surgery for different congenital cardiac anomalies. Premature babies, children above 12 years, those who underwent closed heart operations and emergency surgeries were excluded. A total of 118 children were excluded from the study. Remaining 608 children were included. Fifty-seven children developed renal impairment (AKI) and 34 of them recovered with hemodynamic optimization and diuretic therapy. Remaining 23 children required PD in the postoperative period. The hospital records of these 23 patients, aged 12 years or younger were reviewed. The following data were collected: demographic information, complete

\begin{abstract}
1,2,4 Intensive Care for CTVS, Department of CTVS, CN Centre, All India Institute of Medical Sciences, New Delhi, India

${ }^{3,5-7}$ Department of Cardiothoracic and Vascular Surgery, CN Centre, All India Institute of Medical Sciences, New Delhi, India

Corresponding Author: Manoj Kumar Sahu, Intensive Care for CTVS, Department of CTVS, CN Centre, All India Institute of Medical Sciences, New Delhi, India, Phone: +91-11-26589388, 9911088705 e-mail: drmanojsahu@gmail.com

How to cite this article: Sahu MK, Bipin C, Arora Y, Singh SP, Devagouru V, Rajshekar $\mathrm{P}$, et al. Peritoneal Dialysis in Pediatric Postoperative Cardiac Surgical Patients. Indian J Crit Care Med 2019;23(8):371-375.
\end{abstract}

Source of support: Nil

Conflict of interest: None

cardiac diagnosis, surgical procedures performed, complexity of surgery (classified into 4 risk categories according to Aristotle Comprehensive Complexity score, with category 4 procedures having the highest risk), cardiopulmonary bypass (CPB) and aortic cross clamp (ACC) duration, postoperative complications including mortality, indications of PD, timing of PD initiation, duration of $\mathrm{PD}$, urine output $(\mathrm{UO})$, serum potassium $\left(\mathrm{S} . \mathrm{K}^{+}\right)$and creatinine (S. cr) levels on days 1 to 3 and day of PD termination and PD related complications.

Prolonged PD was defined as the PD duration exceeding 5.5 days and short PD as PD duration of 5.5 days or less in this study ( 5.5 days was the mean PD duration of the study population) . Late PD was defined as the PD initiation 3.5 days after the CSICU admission and early PD as PD initiation 3.5 days before CSICU admission after open heart surgery (3.5 days was the mean time period for PD

() The Author(s). 2019 Open Access This article is distributed under the terms of the Creative Commons Attribution 4.0 International License (https://creativecommons. org/licenses/by-nc/4.0/), which permits unrestricted use, distribution, and non-commercial reproduction in any medium, provided you give appropriate credit to the original author(s) and the source, provide a link to the Creative Commons license, and indicate if changes were made. The Creative Commons Public Domain Dedication waiver (http://creativecommons.org/publicdomain/zero/1.0/) applies to the data made available in this article, unless otherwise stated. 
initiation after ICU admission in this study population). This study was started after obtaining approval from the Institute's Ethics committee, but the consent from individual patients was waived off considering the retrospective nature of the study.

Peritoneal dialysis is the first treatment of choice for AKI in postoperative pediatric cardiac surgical patients at our institution. AKI was defined as decreased urine output $<0.5 \mathrm{~mL} / \mathrm{kg} / \mathrm{h}$ for more than 6 hours or serum creatinine rising more than $0.3 \mathrm{mg} / \mathrm{dl}$ during last 24 hours, despite aggressive diuretic therapy and optimization of inotropic support, or a combination of both (AKIN criteria). ${ }^{9}$ We in our institute do not have a protocol of initiating intraoperative PD prophylactically. Postoperatively PD is initiated whenever it is indicated. Indications for PD included AKI as defined above, severe fluid overload due to third spacing caused by CPB induced severe inflammation, low cardiac output(LCO) situation leading to severe metabolic acidosis( $\mathrm{pH}<7.2$, base deficit $>-10)$ and hyperkalemia ( $\mathrm{K}^{+}$exceeding $5 \mathrm{mEq} / \mathrm{L}$ ). All the patients who developed metabolic acidosis and/or hyperkalemia, were treated medically before initiating peritoneal dialysis. Indications for stopping PD included return of sufficient urine output, normalization of serum electrolytes and acid-base status.

The PD catheter (Romsons scientific and surgical industries Pvt Ltd, Agra, UP, India) was inserted percutaneously through the infraumbilical approach in the CSICU under complete aseptic measures. Initiation of PD was in accordance with the preceding indications. The PD catheter was connected to a closed system for peritoneal drainage. The dialysate solution used were standard commercial preparations (Shree Krishna Keshav Lab Ltd, Ahmedabad, Gujarat, India) with a dextrose concentration of $1.7 \%$. Heparin (500 units/L of dialysate) was added. PD was started with a dwell volume of $10-20 \mathrm{~mL} / \mathrm{kg}$, a fill time of 10 minutes, a dwell time of 30 minutes, a drainage time of 20 minutes and at one hourly cycles. According to the targeted fluid balance, acidosis, hyperkalemia and hemodynamics, the dwell volume, time and PD cycles were changed subsequently if needed. The dialysate bags were changed every 24 hours. Serum albumin was regularly monitored, and intravenous albumin (20\%) infusions were given as necessary.

Data were expressed as median with inter quartile range as the total number of study participants were only 23. Categorical variables were analyzed using Chi-square test or Fischer test, while non-categorical variables were analysed using Man-whitney test or t-test as appropriate. A $p$ value of less than 0.05 was considered statistically significant. All statistical analyses were performed using STATA/SE 14.0 software.

\section{RESULTS}

\section{Demography}

In the present study, 23 patients among the 608 young children who underwent open heart surgery, experienced AKI or excessive fluid load or acidosis and required PD. Thus the prevalence of PD was $3.78 \%$. The surgical procedures performed and their risk categories are shown in Table 1. The mean age of these 23 patients at surgery was 22.12 months (range $0.2-108$ months), and their mean body weight was $8.42 \mathrm{~kg}$ (range $1.8-25.0 \mathrm{~kg}$ ). The mean time interval between surgery and institution of PD was 3.5 days (range 0-15 days), whereas the mean duration of PD was 5.5 days (range, 2-10 days).

\section{Factors Associated with Survival Following PD among Pediatric Cardiac Surgery Patients (Table 2)}

There were a total of $12(52 \%)$ deaths among the 23 who received PD. Factors significantly associated with survival after starting PD

\begin{tabular}{|c|c|c|c|c|c|}
\hline SI. No & Cardiac surgery & $\begin{array}{l}\text { No. of patients } \\
(n=23)\end{array}$ & Age in months & $\begin{array}{l}\text { Risk (surgical } \\
\text { complexity } \\
\text { score) }\end{array}$ & $\begin{array}{l}\text { No of survivors } \\
(n=11) \text { [Survivor }= \\
\text { s/nonsurvivor }=n \text { ] }\end{array}$ \\
\hline 1 & $\begin{array}{l}\text { ASD closure + sliding } \\
\text { Tracheoplasty }\end{array}$ & 1 & 2 & 2 & $1[\mathrm{~s}]$ \\
\hline 2 & ASO & 1 & 3 & 4 & $0[n]$ \\
\hline 3 & ASO+ASD closure & 1 & 2.5 & 4 & $1[s]$ \\
\hline 4 & ASO+ ECMO & 1 & 1 & 4 & $0[n]$ \\
\hline 5 & ASO+VSD closure & 1 & 5 & 4 & $1[s]$ \\
\hline 6 & AVSD repair+ TAP & 3 & $48 / 48 / 84$ & 3 & $2[\mathrm{n} / \mathrm{s} / \mathrm{s}]$ \\
\hline 7 & AVSD repair & 1 & 24 & 2 & $0[\mathrm{n}]$ \\
\hline 8 & DSO & 1 & 108 & 4 & $0[n]$ \\
\hline 9 & ICR & 2 & $36 / 12$ & 2 & $1[n / s]$ \\
\hline 10 & $\mathrm{ICR}+\mathrm{TAP}$ & 3 & $12 / 1 / 48$ & 3 & $2[\mathrm{n} / \mathrm{s} / \mathrm{s}]$ \\
\hline 11 & ICR + TAP + LPA plasty & 1 & 12 & 4 & $0[\mathrm{n}]$ \\
\hline 12 & REV procedure & 1 & 12 & 4 & $0[n]$ \\
\hline 13 & TAPVC repair & 2 & $0.3 / 0.2$ & $2 / 3$ & $1[n / s]$ \\
\hline 14 & Truncus repair & 1 & 24 & 2 & $0[\mathrm{n}]$ \\
\hline 15 & $\begin{array}{l}\text { Truncus repair + } \\
\text { IAA repair }\end{array}$ & 1 & 1 & 4 & $0[\mathrm{n}]$ \\
\hline 16 & $\begin{array}{l}\text { VSD closure } \\
\text { (severe PAH) }\end{array}$ & 1 & 1 & 2 & $1[s]$ \\
\hline 17 & VSD closure + TAP & 1 & 24 & 2 & $1[\mathrm{~s}]$ \\
\hline
\end{tabular}

For the purpose of statistical analysis, scores 1 and 2 were clubbed together as low risk and scores more than two as high risk category 
Table 2: Comparison of clinical variables between survivors and nonsurvivors following peritoneal dialysis

\begin{tabular}{|c|c|c|c|c|}
\hline SINo & Variable & $\begin{array}{l}\text { Survivor }(n=11) \\
\text { Median }(p 25, p 75)\end{array}$ & $\begin{array}{l}\text { Nonsurvivor }(n=12) \\
\text { Median }(p 25, p 75)\end{array}$ & $p$ value \\
\hline 1 & Age in months & $5(1,24)$ & $12(2,42)$ & 0.52 \\
\hline 2 & Sex (no of male : female) & $7: 4$ & $8: 4$ & 0.88 \\
\hline 3 & Weight in kg & $7.6(3.2,10)$ & $9.25(5.7,11)$ & 0.25 \\
\hline 4 & $\begin{array}{l}\text { Complexity of surgery (low : high } \\
\text { score) }\end{array}$ & $6: 5$ & $5: 7$ & 0.54 \\
\hline 5 & Preoperative hospitalization (days) & $3.5(2,11)$ & $6(1,11)$ & 0.94 \\
\hline 6 & CPB time in minutes & $120(114,136)$ & $138(96,150)$ & 0.70 \\
\hline 7 & ACC time in minutes & $75(66,85)$ & $69(64,108)$ & 0.85 \\
\hline 8 & Sternum (open : closed) & $4: 7$ & $4: 8$ & 0.88 \\
\hline 9 & Time of PD initiation in days & $2(1,6)$ & $3(1,4)$ & 0.88 \\
\hline 10 & Days PD ran & $5(4,6)$ & $7.5(4,9)$ & 0.15 \\
\hline 11 & Procalcitonin in $\mathrm{ng} / \mathrm{ml}$ & $10(2,18)$ & $22(15,150)$ & 0.01 \\
\hline 12 & $\begin{array}{l}\text { Sepsis (microbial culture }= \\
\text { Sterile: } \text { Positive) }\end{array}$ & $8: 3$ & $10: 2$ & 0.54 \\
\hline 13 & $\mathrm{~S} . \mathrm{K}+$ day 1 in $\mathrm{mEq} / \mathrm{L}$ & $4.1(3.9,4.9)$ & $4.15(3.9,4.8)$ & 0.97 \\
\hline 14 & $\mathrm{~S} . \mathrm{K}+$ day 2 in $\mathrm{mEq} / \mathrm{L}$ & $4.1(3.6,4.5)$ & $4.95(4.65,5.6)$ & 0.001 \\
\hline 15 & $\mathrm{~S} . \mathrm{K}+$ day3 in $\mathrm{mEq} / \mathrm{L}$ & $3.9(3.6,4.2)$ & $5.1(4.6,5.5)$ & 0.04 \\
\hline 16 & $\begin{array}{l}\mathrm{S} . \mathrm{K}+\text { day of } \mathrm{PD} \text { termination in } \\
\mathrm{mEq} / \mathrm{L}\end{array}$ & $3.87(3.5,4.1)$ & $4.95(4.4,5.25)$ & 0.001 \\
\hline 17 & S.cr. on day1 PD (mg/dL) & $0.6(0.5,1.3)$ & $0.7(0.4,0.9)$ & 0.94 \\
\hline 18 & S.cr. on day2 PD (mg/dL) & $0.9(0.5,1.5)$ & $1.1(0.9,1.3)$ & 0.43 \\
\hline 19 & S.cr. on day3 PD (mg/dL) & $1(0.6,1.3)$ & $1.3(1.15,1.55)$ & 0.25 \\
\hline 20 & S.cr day of PD termination (mg/dL) & $1(0.3,2.2)$ & $1.65(1.55,1.95)$ & 0.32 \\
\hline 21 & UO day 1 of $P D$ in $\mathrm{mL} / \mathrm{kg} / \mathrm{hr}$ & $1.157(0.23,2.9)$ & $1.3(0.61,2.9)$ & 0.60 \\
\hline 22 & UO day 2 of PD in $\mathrm{mL} / \mathrm{kg} / \mathrm{hr}$ & $1.56(0.16,2.6)$ & $0.405(0.055,1.605)$ & 0.31 \\
\hline 23 & UO day 3 of PD in $\mathrm{mL} / \mathrm{kg} / \mathrm{hr}$ & $2.2(0,3.64)$ & $0(0,0.245)$ & 0.03 \\
\hline 24 & $\begin{array}{l}\text { UO day of PD termination in } \mathrm{mL} / \\
\mathrm{kg} / \mathrm{hr}\end{array}$ & $2.5(1,4.1)$ & $0.0915(0.0175,0.21)$ & 0.18 \\
\hline
\end{tabular}

were serum procalcitonin $(p=0.01)$, serum potassium on day 2 ( $p=$ $0.005)$, day $3(p=0.04)$, day of stopping the $\mathrm{PD}(p=0.001)$ and urine output on day 3 of PD $(p=0.03)$.

\section{Factors Associated with Longer PD duration among Pediatric Cardiac Surgery Patients (Table 3)}

Factors significantly associated with a longer duration of PD were time of PD initiation ( $p=0.01)$, a higher postoperative serum creatinine on day 3 of PD ( $p=0.01)$, on the day of PD termination $(p=0.01)$. Short duration PD was associated with decreased mortality during the postoperative period $(p=0.02)$. In our study the odds ratio between the two groups of short duration and prolonged PD considering the complexity of surgery was $5.3(95 \% \mathrm{Cl}=0.8911$ to $31.9191, p=0.05$ ).

\section{Factors Associated with Early PD Initiation among Pediatric Cardiac Surgery Patients (Table 4)}

Factors significantly associated with an early PD initiation were CPB time $(p=0.04)$, culture positive sepsis $(p=0.02)$ and short PD duration $(p=0.003)$. And based on observations in Tables 3 and 4 , it was found that early PD initiation was associated with lesser number of days of PD.

\section{Complications}

PD and procedure related complications like peritonitis, or bleeding or bowel injury were not found in this subset of patients. Three children had mechanical problems of PD catheter misplacement/ malfunction needing repositioning/change.

\section{Discussion}

PD is a dependable, safe and effective method for treating AKI in young children in the postoperative period after open heart surgery. AKI in this subset of patients mostly related to the complex congenital pathology requiring longer extracorporeal circulation time for repair of the defects, the cyanosis, CPB induced inflammation and sepsis. ${ }^{4-6}$

The reported prevalence of $A K I$ requiring $P D$ in children after cardiac surgery with CPB range from 1.6 to $9 \% .^{1-5,10}$ In our study the prevalence of $A K I$ requiring PD was $3.78 \%$, similar to the previous studies. The mortality rate of our patients undergoing PD was relatively high at $52 \%$, even though it matches with previously described studies with rates of 27 to $79 \%{ }^{1,4,7,11,12}$ The high death rate in our cohort of patients was probably because of longer CPB, LCO and sepsis. 
Table 3: Comparison of clinical variables between short PD and prolonged PD

\begin{tabular}{lllll}
\hline & & Short PD $(n=12)$ & Long PD $(n=11)$ & $p$ \\
SI No & Variable & Median $(p 25, p 75)$ & Median $(p 25, p 75)$ & value \\
\hline 1 & Age in months & $12(2.25,42)$ & $5(1,24)$ & 0.42 \\
2 & Sex (no of male : female) & $8: 4$ & $7: 4$ & 0.88 \\
3 & Weight in kg & $8.25(5.4,10.25)$ & $7.8(3.6,10)$ & 0.59 \\
4 & Complexity of surgery (low : high & $8: 4$ & $3: 8$ & 0.05 \\
& score) & & & \\
5 & Preoperative hospitalization (days) & $4(1,6)$ & $10(1,11)$ & 0.30 \\
6 & CPB time in minutes & $117.5(105,137)$ & $140(96,148)$ & 0.75 \\
7 & ACC time in minutes & $73.5(63,85.5)$ & $66(66,96)$ & 0.97 \\
8 & Open sternum: closed sternum & $3: 9$ & $5: 6$ & 0.30 \\
9 & Time of PD initiation in days & $1(1,3)$ & $4(3,7)$ & 0.01 \\
10 & No of survivors: nonsurvivors & $8: 4$ & $3: 6$ & 0.02 \\
11 & Procalcitonin in ng/ml & $12.5(2,20)$ & $22(15,150)$ & 0.06 \\
12 & Microbial culture(Sterile:Positive) & $11: 1$ & $7: 4$ & 0.10 \\
13 & S.cr. on day 1 PD (mg/dL) & $0.6(0.4,0.8)$ & $0.7(0.5,1.3)$ & 0.52 \\
14 & S.cr. on day 2 PD (mg/dL) & $0.9(0.5,1.25)$ & $1.2(0.9,1.5)$ & 0.12 \\
15 & S.cr. on day 3 PD (mg/dL) & $1(0.65,1.4)$ & $1.5(1.3,1.9)$ & 0.01 \\
16 & S.cr. on day of PD termination (mg/dL) & $1.1(0.4,1.7)$ & $1.8(1.6,2.2)$ & 0.01 \\
\hline
\end{tabular}

Table 4: Comparison of clinical variables between early PD and late PD

\begin{tabular}{cllll}
\hline & & Early PD $(n=15)$ & Late PD $(n=8)$ & $p$ \\
SI No & Variable & Median $(p 25, p 75)$ & Median $(p 25, p 75)$ & value \\
\hline 1 & Age in months & $12(1,36)$ & $4(1.5,36)$ & 0.62 \\
2 & Sex (male : female) & $10: 5$ & $5: 3$ & 0.84 \\
3 & Weight in kg & $8(3.6,10)$ & $7.05(3.05,11)$ & 0.87 \\
4 & Complexity of surgery (low : high & $7: 8$ & $4: 4$ & 0.88 \\
& score) & & & \\
5 & Preoperative hospitalization(days) & $3(1,6)$ & $10(4.5,11)$ & 0.09 \\
6 & CPB time in minutes & $136(114,146)$ & $96(40,136)$ & 0.04 \\
7 & ACC time in minutes & $76(66,96)$ & $66(48,66)$ & 0.07 \\
8 & Open sternum : closed sternum & $5: 10$ & $3: 5$ & 0.84 \\
9 & No of survivors: nonsurvivors & $7: 8$ & $4: 4$ & 0.88 \\
10 & Days PD ran & $5(3,6)$ & $8.5(6,9.5)$ & 0.003 \\
11 & Procalcitonin in ng/mL & $15(8,22)$ & $19(8.5,125)$ & 0.53 \\
12 & Microbial culture(Sterile:Positive) & $14: 1$ & $4: 4$ & 0.02 \\
13 & S.cr. on day 1 PD (mg/dL) & $0.6(0.3,0.9)$ & $0.6(0.5,1.3)$ & 0.64 \\
14 & S.cr. on day 2 PD (mg/dL) & $0.9(0.5,1.3)$ & $1.05(0.8,1.45)$ & 0.53 \\
15 & S.cr. on day 3 PD (mg/dL) & $1.3(0.7,1.6)$ & $1.3(1.15,1.7)$ & 0.36 \\
16 & S.cr day of PD termination (mg/dL) & $1.5(0.5,1.8)$ & $1.8(1.65,2.15)$ & 0.07 \\
\hline
\end{tabular}

In our study, factors significantly associated with survival following PD were serum procalcitonin levels, serum potassium on day 2, day 3, day of PD termination and urine output on day 3 of PD. However Guiffre et al compared clinical variables between survivors and nonsurvivors after PD and did not find any pre, intra or postoperative variables as risk factors. ${ }^{13}$ On the other hand, Chan et al. ${ }^{14}$ found that associated syndromes (Down's, DiGeorge's), requirement of preoperative ventilation, a higher postoperative ventilatory settings and LCOS were significant risk factors. As per Chien et al, risk factors included CPB \& ACC time, $\mathrm{pH}$, bicarbonate and base deficit before beginning $P D$, intervals between acute renal failure (ARF) and PD, PD and peak creatinine, PD and urine output on recovery, duration of inotropic agents, time of mechanical ventilation and duration of hyperglycemia. ${ }^{15}$ We in our study could not demonstrate any direct association between the preoperative hospital admission $(p>0.05)$, delayed sternal closure $(p>0.05)$ and the duration of PD and survival. One child with AVSD and PS was a case of Down's syndrome who did not survive, but we did not study on this aspect to comment on syndromes and their association with AKI.

We further determined factors associated with a longer duration of PD and those were the time of PD initiation, a higher postoperative serum creatinine on day 3 of PD, the day of PD termination. Also short duration PD had a significant survival advantage in the postoperative period. According to Chan et al, risk factors identified were younger age, higher preoperative serum creatinine, postoperative LCOS, pulmonary hypertensive crisis and a higher oxygen requirement. ${ }^{14}$ Chien et al. demonstrated that postoperative LCOS, prolonged inotropic therapy, postoperative ventilator settings, sepsis, disseminated intravascular coagulopathy, 
and multiple organ failure were the risk factors. ${ }^{15}$ In our study the odds ratio between the two groups of short duration and prolonged PD considering the complexity of surgery showed that children with higher surgical complexity score required longer duration of PD. Similar findings have been reported in the past by Dittrich et al. as $\mathrm{AKI}$ is often related to cyanotic heart disease, complex congenital cardiac anomalies and their operation, longer CPB time. ${ }^{16}$

The optimal timing for PD intervention is still controversial. Many authors have suggested that early intervention with PD is needed as soon as ARF occurs. ${ }^{2,11,17}$ Chien et al. from their study found that, the time to initiate PD in survivors was significantly earlier than that in nonsurvivors. ${ }^{15}$ We in our study demonstrated that early PD initiation was associated with lesser number of days of PD. The CPB time, culture positive sepsis and PD duration were the significant factors found to be associated with an early initiaton of PD in the present study. However we did not find any statistically significant survival benefit with early PD initiation.

Dittrich et al. ${ }^{18}$ in their study showed that PD can be performed safely in smaller children without affecting hemodynamics negatively, we too did not come across any major problems in the performance of PD. Though the serum creatinine decreased very slowly, those were normalized in all the surviving children and this was in agreement with other studies. ${ }^{3,10}$

\section{Study Limitations}

Retrospective nature of this study was a drawback. Enrollment of small number of patients requiring PD in our study caused a low statistical power and we could not apply multivariate analysis to assess risk factors for prolonged PD and mortality. Some studies have highlighted the beneficial effects of PD on hemodynamics and cardiovascular function, ${ }^{1,18}$ which could have been assessed in a prospective manner. Hence more prospectively designed studies with larger number of study participants are needed to investigate the risk factors of prolonged PD and mortality in pediatric cardiac surgical patients with AKI.

\section{ConCLUSION}

PD is very effective in achieving fluid, electrolyte and acid-base balance without causing significant hemodynamic compromise with minimal or no complications. Sepsis biomarker positivity (high PCT values) seem to be one of the major associated factors of postoperative mortality following PD. Short duration PD was associated with decreased mortality during the postoperative period. Early PD initiation seemed to have advantages in terms of reducing the total duration and subsequent morbidity.

\section{References}

1. Werner HA, Wensley DF, Lirenman DS, LeBlanc JG. Peritoneal dialysis in children after cardiopulmonary bypass. J Thorac Cardiovasc Surg1997;113:64-68.
2. Sorof JM, Stromberg D, Brewer ED, Feltes TF, Fraser CD. Early initiation of peritoneal dialysis after surgical repair of congenital heart disease. Pediatr Nephrol 1999;13:641-645.

3. Kist-van Holthe tot Echten JE, Goedvolk CA, Doornaar MB, van der Vorst MM, Bosman-Vermeeren JM, Brand R,et al. Acute renal insufficiency and renal replacement therapy after pediatric cardiopulmonary bypass surgery. Pediatr Cardiol 2001; 22:321-326.

4. Ridgeden SP, Barrat TM, Dillon MJ, de Leval M, Stark J. Acute renal failure complicating cardiopulmonary bypass surgery. Arch Dis Child 1982;57:425-430.

5. Hanson J, Loftness S, Clarke D, Cambell D. Peritoneal dialysis following open heart surgery in children. Pediatr Cardiol 1989;10:125-128.

6. Abel RM, Buckley MJ, Austen WG, Barnett GO, Beck CH Jr, Frischer JE. Etiology, incidence and prognosis of renal failure following cardiac operations. J Thorac Cardiovasc Surg 1986;71:323-3.

7. Fleming F, Bohn D, Edwards H, Cox P, Geary D, Mc Crindle BW, et al. Renal replacement therapy after repair of congenital heart disease in children. A comparison of hemofiltration and peritoneal dialysis. J Thorac Cardiovasc Surg 1995; 109:322-331.

8. Paret G, Cohen AJ, Bohn DJ, Edwards H, Taylor R, Geary D, et al. Continuous arteriovenous hemofiltration after cardiac surgery operations in infants and children. J Thorac Cardiovasc Surg 1992;104:1225-1230.

9. Mehta RL, Kellum JA, Shah SV, Molitoris BA, Ronco C, Warnock DG, et al. Acute Kidney Injury Network: report of an initiative to improve outcomes in acute kidney injury. Crit Care. 2007;11:31.

10. Shaw NJ, Brocklebank JT, Dickinson DF, Wilson N, Walker DR. Longterm outcome for children with acute renal failure following cardiac surgery. Int J Cardiol 1991;31:161-166.

11. Dittrich S, Da“hnert I, Vogel M, Stiller B, Hass NA, Alexi-Meskishvili V, et al. Peritoneal dialysis after infant open heart surgery: observations in 27 patients. Ann Thorac Surg1999; 68:160-163.

12. Reznik VM, Griswold WR, Peterson BM, Rodarte A, Ferris ME, Mendoza SA. Peritoneal dialysis for acute renal failure in children. Pediatr Nephrol 1991; 5:715-717.

13. Giuffre RM, Tam KH, Williams WW, Freedom RM. Acute renal failure complicating pediatric cardiac surgery: a comparison of survivors and non survivors following acute peritoneal dialysis. Pediatr Cardiol 1992;13:208-214.

14. Chan K, Patrick Ip, Chiu CSW, Cheung YF. Peritoneal Dialysis After Surgery for Congenital Heart Disease in Infants and Young Children. Ann Thorac Surg2003; 76:1443-1449.

15. Chien JC, Hwang BT, Weng ZC, Meng LC, Lee PC. Peritoneal dialysis after open heart surgery. Pediatr Neonatol 2009; 50(6):275-279.

16. Dittrich S, Kurschat K, Dahnert I, Vogel M, Müller C, Alexi-Meskishvili $V$ et al. Renal function after cardiopulmonary bypass surgery in cyanotic congenital heart disease. Int J Cardiol 2000; 73:173-179.

17. Lin MC, Fu YC, Fu LS, Jan SL, Chi CS. Peritoneal dialysis in children with acute renal failure after open heart surgery. Acta Paediatr Taiwan 2003; 44:89-92.

18. Dittrich S, Vogel M, Dahnert I, Hass NA, Alexi-Meskishvili V, Lange PE. Acute hemodynamic effects of post cardiotomy peritoneal dialysis in neonates and infants. Intensive Care Med 2000; 26:101-104. 